\title{
Em tempos de ódio emergente e candente, à reflexão
}

Mateus Pranzetti Paul Gruda?

\section{Resenha Do livro:}

GALLEGO, Esther Solano (org.). O ódio como política: a reinvenção das direitas no Brasil. São Paulo: Boitempo, 2018. 117p.

Penúltimo lançamento da coleção "Tinta Vermelha”, da editora Boitempo, "O ódio como política: a reinvenção das direitas no Brasil" (2018), organizado por Esther Solano Gallego, tal como nos outros títulos da citada coleção, propõe apontamentos e reflexões acerca de tópico extremamente quente e atual, tendo a particularidade de serem editados e publicados justamente em meio aos acontecimentos que se propõe a debater (a fim de ilustração, as obras que compõem a coleção versaram sobre: o movimento dos Occupy [2012]; as manifestações de junho de 2013 [2013]; os megaeventos - Copa do Mundo e Olimpíadas - que aconteceriam no Brasil [2014]; a violência policial brasileira [2015]; o processo de remoção da presidenta Dilma Rousseff [2016]; e a defesa da educação pública, gratuita e democrática [2019]). Neste compilado - o qual poderíamos denominar, sem receio de incorrer em erro, por um "livro-intervenção" - que aqui resenhamos, o foco é a onda conservadora mundial que também impacta e produz efeitos no Brasil por meio, sobretudo, da emergência de uma, por assim dizer, nova direita - ou, melhor seria escrever e pensar neste termo no plural, "direitas", pois, ao menos seguindo a chave de entendimento da dialética e da complexidade, tudo detém aspectos de multiplicidade e heterogeneidade, ao

1 Universidade Estadual Paulista (UNESP) - Assis - Brasil - mateusbeatle@hotmail.com 
contrário da perspectiva de compreender os processos e coisas como sendo tão-somente monolíticas e completamente homogêneas. Este fenômeno do fortalecimento e espraiamento do pensamento conservador de direita que já é possível de ser percebido ao redor do mundo nas últimas décadas, em nosso país tem se tornado cada vez mais visível, tanto nos tantos aspectos do ponto de vista de ideias econômicas, jurídicas etc. quanto em episódios (organização de institutos/think tanks, perseguição às minorias, ataques à exposição de arte, para mencionar apenas alguns) arrolados ao longo dos textos contidos nesta coletânea de artigos agora publicada. Sem podermos deixar de também mencionar o quanto isto impacta e se materializa enquanto realidade social e subjetiva nos últimos pleitos eleitorais brasileiros, mormente, nas eleições majoritárias ocorridas no mês de outubro de 2018.

Os dezessete textos de "O Ódio como Política: a reinvenção das direitas no Brasil” nos apontam para uma multiplicidade de abordagens e fios de discussão a serem puxados frente ao tema central, ainda que em nota da própria editora fique expressa uma única convergência: "não há autores de direita entre os dezoito que colaboram com o livro." (Gallego, 2018: 11), característica a qual poderia ser imputada como problemática por indicar uma possibilidade de pensamento único contaminado por conceitos e ideias pré-concebidas e que impediriam reflexionar sobre o fenômeno que se propõe analisar e discutir, entretanto, seguindo na mesma nota da editora, tal significativo impasse é dirimido: "No entanto, todos eles buscaram mergulhar nesse universo, de certa forma novo e assustador, sem qualquer preconceito, com o desejo honesto de conhecer e interpretar seu significado." (Gallego, 2018: 11). Ao percorrermos todas as contribuições textuais, podemos de um modo geral confirmar tal assertiva inicial da editora, uma vez que os autores e autoras discutem aspectos destas direitas emergentes sem demonizá-las a prioristicamente, o que, obviamente, não exclui haver demarcação dos contrapontos existentes, os quais são desdobrados teoricamente e com base em argumentos articulados.

Antes de passarmos a comentar acerca do conjunto de colaborações presentes na obra, indicamos o prólogo redigido pelo ator e escritor Gregório Duvivier, o qual, ainda que bastante sintético, se assemelha a um manifesto em que, de modo contundente, denuncia alguns dos pilares de sustentação de certa perspectiva da direita conversadora, justamente aqueles que têm sido defendidos ferrenhamente por boa parte de quem se reivindica a se posicionar neste campo e espectro ideológico - e, frente ao nível e condições de discussões atuais envolvendo tal termo/ideia (ideologia), é importante enfatizar, como tantos autores o fizeram ao longo da história do pensamento (Žižek, 1996), que é impossível 
viver fora da ideologia, sendo aquela frase gasta e clichê necessária de ser reafirmada - o que nos lembra, inclusive, da indagação atribuída ao dramaturgo e poeta alemão Bertold Brecht (1890-1956) "que tempos são esses que temos que defender o óbvio?”, a qual, devemos concordar, nunca foi tão atual - se afirmar fora da ideologia já é um ato altamente ideológico. As treze contundentes linhas de Duviver ao lado de uma charge crítica (e não menos contundente) à operação Lava-Jato da cartunista Laerte iniciam a obra nos indicando que, sim, estamos diante de um livro-intervenção e que nos preparemos para movimentar nosso senso e pensamento críticos.

Agora sim, debruçando-nos panoramicamente (reforçando que destacaremos alguns dos pontos de cada texto, não a totalidade de discussões presentes. Para apreensão aprofundada, evidentemente, recomendamos a leitura do livro) acerca dos textos que compõem o compilado: no primeiro, "A reemergência da direita brasileira", Luis Felipe Migual discorre sobre os aspectos centrais desta reemergência (o libertarianismo, o fundamentalismo religioso e a reciclagem do sentimento anticomunista); em "Neoconservadorismo e liberalismo", de Silvio Luiz de Almeida, o autor coloca em perspectiva as ideias de liberalismo e conservadorismo e suas atualizações para receberem o prefixo NEO, criticando que sob as condições materiais de existência que perduram, é pouco crível falar em liberdades; em "A nova direita e a normalização do nazismo e do fascismo", Carapanã tece um paralelo entre a reciclagem do sentimento anticomunista (discutida no primeiro texto, como mencionamos), a qual, para o autor, não é o principal da nova direita, pois esta "[...] flerta com ideias do nazifascismo e, consciente ou inconscientemente contribui para normalizá-las. Quando são criticados por esses aspectos se refugiam em questões de 'liberdade de expressão' e de uma suposta 'hegemonia de esquerda." (Gallego, 2018: 39); em "As classes dominantes e a nova direita no Brasil contemporâneo", Flávio Henrique Calheiros Casimiro discorre sobre o projeto de reorganização das classes dominantes que se materializa em um modo de ação política-ideológica bastante perceptível na atualidade, fundamentada, dentre outras coisas, pela afirmação de apartidarismo e neutralidade, da truculência disseminada pelas redes sociais etc.; no texto seguinte, "O boom das novas direitas brasileiras: financiamento ou militância?", Camilo Rocha discute que, para além das possibilidades de recursos financeiros e de exposição midiática volumosos, a ascensão das direitas também estão associadas com outros fatores, como a disseminação do medo na opinião pública (notemos que o revivalismo de um sentimento de temor a um suposto comunismo se faz presente, ainda que de modo lateral, em mais uma das análises), a força de articulação nas redes sociais da militância, dentre outros. 
Em "Da esperança ao ódio a juventude periférica bolsonarista", Rosana Pinheiro-Machado e Lucia Mury Scalco relatam um estudo etnográfico longitudinal, realizado desde 2009 na periferia de Porto Alegre, em que discutem política e consumo com os(as) jovens que habitam esse espaço urbano, perpassando pelas tendências evocadas pelas categorias esperança e ódio; o texto subsequente, "Periferia e conservadorismo", do Ferréz, é uma crônica sobre as condições periclitantes que favorecem o espraiamento do discurso reacionário, a dificuldade em argumentar contra as explorações vivenciadas, a manipulação midiática e o quão multifacetada é a periferia, sendo este último aspecto reflexionado dialeticamente, pois, ao mesmo tempo que há multiplicidade há uma permanência e previsibilidade únicas, segundo o autor, o caos; em "A produção do inimigo e a insistência do Brasil violente e de exceção", Edson Telles enfatiza o quanto a militarização e o militarismo são padrões na organização social e subjetiva do nosso país, justificando o genocídio de determinadas populações, perseguição e criminalização de qualquer ato de resistência à ordem hegemônica e dominante, a criação do antagonismo cidadão de bem versus vagabundos, e se imiscuindo nos discursos e práticas sociais cotidianas; em "Precisamos falar da direita jurídica”, Rubens Casara discute a ideia de que o direito serve à manutenção da ordem dominante e de que há uma tendência conservadora neste, trazendo reflexões sobre o ativismo judicial (tópico que é extremamente candente na atualidade em que provas são menos importantes do que conviç̧ões), sobre "a adesão do mundo jurídico à racionalidade neoliberal” (Gallego, 2018: 76), além de uma crítica a quanto o poder judiciário permite o arbítrio antidemocrático, ao invés de coibi-lo, e, para tal, mobiliza inclusive o conceito de personalidade autoritária, de Adorno.

Já em "O discurso econômico da austeridade e os interesses velados", de Pedro Rossi e Esther Dweck, a autora e o autor recuperam as raízes filosóficas do termo austeridade para demostrar que este não se ancora ou advém do léxico econômico, também questionam o que geralmente sustenta o tal discurso da austeridade, se debruçando sobre duas ideias principais ("a metáfora do orçamento doméstico" e a "fada da confiança") e indicam que este discurso é um dos três pilares do neoliberalismo (os outros seriam a liberalização dos mercados e as privatizações); o artigo seguinte, "Antipetismo e conservadorismo no Facebook", de Márcio Moretto Ribeiro, apresenta uma investigação de buscar características prototípicas de pessoas que poderiam compor um grande grupo, o dos "antipetistas", mergulhando em páginas do Facebook alinhadas à visão conservadora de mundo e com números expressivos de interações por parte dos usuários; em "Fundamentalismo e extremismo não esgotam a experiência 
do sagrado nas religiões", Henrique Vieira joga luz na importância de se discutir as concepções de mundo do fundamentalismo religioso, o qual cada vez mais tem se associado ao poder político e midiático e tido força para influenciar nas pautas institucionais e discussões e rumos nacionais. Alguns dos pontos reflexionados são a ideia de verdade absoluta, inquestionável, e a história, a conexão entre medo e culpa, a intolerância com a multiplicidade e diferenças, bem como a reivindicação da pluralidade envolvida na história do cristianismo.

Em "Moralidades, diretas e direitos LGBTI nos anos 2010", de Lucas Bulgarelli, o autor recupera e analisa eventos recentes envolvendo os direitos da população LGBTI, sublinhando o quanto a aliança entre os setores conservadores (nomeadamente a chamada bancada evangélica na câmara federal) negam qualquer avanço nos direitos dessas pessoas ao barrarem qualquer projeto de lei neste sentido, citando a disputa envolvendo a exposição Queermuseu, em Porto Alegre, e da reação à visita da filósofa Judith Butler ao Brasil (ambos eventos corridos no segundo semestre de 2017) e fazendo menção aos equívocos relativos à expressão "ideologia de gênero"; o texto "Feminismo: um caminho longo à frente", Stephanie Ribeiro chama atenção para pautas candentes e necessárias, como a questão do direito ao aborto seguro e legal, o feminicídio, a importância de não excluir as opressões de raça e gênero na crítica e luta por transformações sociais, uma autocrítica ao feminismo "pop", maiormente disseminado pelas redes sociais, além de comentar o processo de impeachment da presidenta Dilma Rousseff e o assassinato da vereadora Marielle Franco; por fim, o último texto, "O discurso reacionário de defesa de uma 'escola sem partido", de Fernando Penna, discorre sobre o projeto Escola Sem Partido, debatendo o quanto este não está sepultado mesmo após ter sido considerado inconstitucional e nos apresentando razões para se posicionar de modo contrário a tal ideia.

Outro aspecto que vale mencionarmos é que neste volume da coleção, tal qual ocorre igualmente nos outros livros que integram esta, encontramos charges dispostas ao longo das páginas, o que, neste mundo em que o código humorístico se imiscui por toda parte (Gruda, 2017; Lipovetsky, 2005), tanto não nos estranha a presença delas no livro-intervenção quanto entendemos relevante o emprego destes textos visuais. Inclusive, ao contrário do humor meramente eufórico, light e/ou carente de potência crítica, o qual maiormente estrutura as relações sociais contemporâneas - tal como indicado na ideia de "sociedade humorística”, de Lipovetsky (2005), ainda nos anos 1980 -, as produções gráficas que compõem "O ódio como política" apresentam sinteticamente um olhar afiado e de questionamento contundente a aspectos defendidos pelas novas direitas. Desse modo, ao contrário de meramente ilustrar o livro-intervenção ou 
produzir riso nas leitoras e leitores, as charges são instrumentos tão ou mais fecundos de análises do tópico central da obra.

Como delineado pela organizadora do livro na apresentação e mesmo em diversas intervenções públicas - entrevistas, palestras e participações em mesas redondas - disponíveis online, se faz necessário compreender profundamente as dinâmicas das direitas por meio da reflexão crítica e, principalmente, escutando as pessoas que se associam a tal cosmovisão. Nos próprios dizeres de um dos participantes de uma das pesquisas da organizadora: "Professora, vocês da acadêmica estudam tanto e parece que ainda não entenderam muitas coisas. Tratam a gente como se fôssemos todos burros. Não somos. Deveriam escutar mais, porque vocês não sabem de tudo." (Gallego, 2018: 13).

Destarte, em um momento em que o tecido social brasileiro se encontra explicitamente fraturado, a ponto de termos tido não apenas, provavelmente, as eleições mais polarizadas de nossa história, como por conta do sentimento candente de ódio entre as pessoas, escutar e tentar compreender, talvez, seja de fato um grande desafio. Valendo a ressalva, que esse tipo de perspectiva não inclui aceitar e relativizar, por exemplo, a intolerância e o desrespeito aos direitos humanos. Nisso, é sempre válido relembrar o "paradoxo da tolerância", de Popper (1998), em que a tolerância ilimitada, estendida aos intolerantes, desemboca na extinção da própria tolerância. Ainda sobre o processo de polarização e clima de ódio vigentes, é possível notar o quanto ambos têm galgado níveis insuportáveis para a convivência nas mais diversas instâncias da vida cotidiana (as discussões e rompimento entre familiares e amigos e amigas de longa data atestam isso) e já estão desembocando no aumento exponencial de agressões físicas (incluindo pessoas assassinadas) perpetradas por determinados grupos localizados em um campo específico do espectro ideológico - há um levantamento realizado por parte da Agência Pública (2018) acerca de agressões ocorridas nos dois turnos das eleições de 2018, que recomendamos que seja acessado. Assim sendo, frente a tal cenário em que não temos disputas de projetos ou debate de ideias, a reflexão crítica envolvendo esses fenômenos e movimentos emergentes na organização política contemporânea pode ser uma ação profícua para ocorrer, ao menos, uma civilização dos conflitos, os quais, sem dúvida, não devem ou precisam ser apagados, uma vez que, seguindo a perspectiva aqui adotada, as contradições constituem a vida. Conquanto e para além disso, como escreve Esther Gallego (2018: 13), "não é possível ficar numa postura desorientada e titubeante, sob o risco de as forças democráticas serem engolidas por aquilo que deveríamos combater com veemência.” À leitura, à reflexão, à ação. 


\section{Referências}

AGÊNCIA PÚBLICA. Violência eleitoral recrudesceu no segundo turno. Pública Agência de Jornalismo Investigativo, 12 nov. 2018. Disponível em: <https://apublica. org/2018/11/violencia-eleitoral-recrudesceu-no-segundo-turno/>. Acesso em: 18 set. 2019.

GALLEGO, Esther Solano (org.). O ódio como política: a reinvenção das direitas no Brasil. São Paulo, Boitempo, 2018 (128).

GRUDA, Mateus Pranzetti Paul. 0 discurso do humor politicamente incorreto no mundo contemporâneo. São Paulo, Cultura acadêmica, 2017. (247)

LIPOVETSKY, Gilles. A era do vazio. Trad. Theresinha Deutsch. Barueri, SP, Manole, 2005 (224).

POPPER, Karl. A sociedade aberta e seus inimigos. Trad. Milton Amado. Belo Horizonte, Ed. Itatiaia, 1998.

ŽIŽEK, Slavoj. (org.). Um mapa da Ideologia. Trad. Vera Ribeiro. Rio de Janeiro, Contraponto, 1996 (337).

Recebido em: 22/10/2018

Aprovado em: 17/05/2019

\section{Como citar esta resenha:}

GRUDA, Mateus Pranzetti Paul Gruda. Em tempos de ódio emergente e candente, à reflexão. Contemporânea - Revista de Sociologia da UFSCar, v. 9, n. 3, set. - dez. 2019, pp. 1015-1021. 